\title{
Nurses' perspective on spiritual leadership: A qualitative study based on Fry's spiritual leadership model
}

Parivash Jahandar ${ }^{1}$, Mansoureh Zagheri Tafreshi ${ }^{2}$, Maryam Rassouli ${ }^{3}$, Foroozan Atashzadeh-Shoorideh ${ }^{4}$, Amir Kavousi $^{5}$

${ }^{1} \mathrm{PhD}$ Student in Nursing, Department of Nursing, School of Nursing and Midwifery, Shahid Beheshti University of Medical Sciences, Tehran, Iran

${ }^{2}$ Associate Professor, PhD in Nursing, Department of Nursing Management, School of Nursing and Midwifery, Shahid Beheshti University of Medical Sciences, Tehran, Iran

${ }^{3}$ Associate Professor, PhD in Nursing, Department of Pediatrics Nursing, School of Nursing and Midwifery, Shahid Beheshti University of Medical Sciences, Tehran, Iran

${ }^{4}$ Associate Professor, Department of Nursing Management, School of Nursing and Midwifery, Shahid Beheshti University of Medical Sciences, Tehran, Iran

${ }^{5}$ Associate Professor, $\mathrm{PhD}$ in Biostatistics, School of Health, Safety and Environment, Shahid Beheshti University of Medical Sciences, Tehran, Iran

\section{Type of article: Original}

\begin{abstract}
Background: Spiritual leadership and spirituality in organizations have the capacity to develop individual and organizational outcomes. This concept, as a newly established paradigm, has many ambiguities and definitions highly affected by cultural contexts.

Objective: This study aimed at determining the concept of spiritual leadership from nurses' perspective and recognizing aspects of spiritual leadership model in the Iranian nurses' sociocultural context, to achieve a common and comprehensive understanding of the concept under study.

Methods: This qualitative study used a directed content analysis method. The participants of this study were 14 managers and nurses employed at different wards of hospitals affiliated to medical universities of Tehran, and were selected using purposive sampling method on the basis of inclusion criteria. The data were collected via individual, deep, and semi-structured interviews from October 2015 to March 2016.

Results: In this study, 14 participants were interviewed, 11 females and three males aged between 26 and 52 years old with a mean working experience of 13 years. After data analysis, 33 subcategories were distilled which fell into nine categories and three main categories including "spiritual leadership", "spiritual well-being", and "organizational consequences". The findings indicated that spiritual leadership can, through application of intrinsic motivation, help develop individual and organizational outcomes by the use of elements of extrinsic motivation in organizational learning.

Conclusion: Nursing managers and nurses expunged upon various dimensions of spiritual leadership. The elements of extrinsic motivation and organizational learning have the potential to develop spiritual leadership. The nursing leaders can use this potential to foster the outcomes of nursing services.

Keywords: Spirituality, Leadership, Motivation, Nurse; Qualitative research
\end{abstract}

\section{Introduction}

Organizations require strong leadership and management to achieve maximum effectiveness (1). Effective leaders are able to influence others by developing visions of the future. These leaders inspire, motivate, and empower staff

\section{Corresponding author:}

Associate Professor Dr. Mansoureh Zagheri Tafreshi, Department of Nursing Management, School of Nursing and Midwifery, Shahid Beheshti University of Medical Sciences, Tehran, Iran.

Tel:+98.2188202519, Fax:+98.2188202518, Email: m.z.tafreshi@sbmu.ac.ir, and tafreshi45@hotmail.com

Received: December 27, 2016, Accepted: March 12, 2017, Published: November 2017

iThenticate screening: February 22, 2017, English editing: March 19, 2017, Quality control: September 28, 2017

This article has been reviewed / commented by Three experts

(C) 2017 The Authors. This is an open access article under the terms of the Creative Commons Attribution-NonCommercialNoDerivs License, which permits use and distribution in any medium, provided the original work is properly cited, the use is non-commercial and no modifications or adaptations are made. 
toward goal attainment in the organization (2). In recent years, more attention has been paid to the spiritual characteristics of leadership, and how leaders establish mutual and appropriate spiritual relationships with employees (3). Spirituality, as a natural aspect of human nature (4), is considered to be an inherent capacity of humans to achieve excellence when a person is placed in a position beyond his ego. It is acquired by resorting to the sacred and whatever that facilitates communication, target, and collaboration (5). Spiritual leadership is defined as the values, attitudes, and behaviors that are necessary to intrinsically motivate oneself and others so that they have a sense of spiritual well-being through calling and membership (6). It encompasses a motivating and inspiring employer with an excellent vision and a corporate culture based on altruism (7). The purpose of spiritual leadership is to have a creative vision in which leaders and followers experience a sense of meaning so that their lives have purpose and difference and to establish culture based on values of altruism, which is felt by leaders and workers as belonging, membership, and a sense of understanding $(7,8)$. It should raise higher levels of main individual and organizational outcomes such as organizational productivity and commitment, fiscal performance, worker life satisfaction, social accountability, self-career management, organizational civil behavior, attachment, and loyalty (7, 9). The nursing staff is an important component of health-care systems (10) and nursing managers, who lead the largest groups of employees in many health-care organizations, play vital roles in defining the organization's mission, vision, and values (11). Studies have shown that appropriate leadership styles are associated with nursing staff retention, creating healthy work environments, job satisfaction, nurses' commitment, and patient satisfaction (12). Spiritual leadership has the potential to revolutionize the nursing environment, promote retention, increase productivity, and provide meaning and purpose in work for nurses (13). The integration of spirituality and leadership is creating new challenges and opportunities for nursing leaders (14). Fry's spiritual leadership model is a causal theory that is developed from the intrinsic motivation theory, and is established on features such as hope, faith, and altruistic love (15). Nursing leaders are required to use suitable leadership models to achieve organizational goals and to show reliable paths to nurses in this process. In this regard, the spiritual leadership model has been recognized as one of the effective leadership methods in the past decade which may lead to promoted individual and organizational outcomes $(7,16-20)$. To apply the spiritual leadership model in the organizational context of the country's nursing community, considering that leadership is a social phenomenon related to social context (19), and that various aspects of spiritual leadership are not known clearly, it is mandatory to first determine the concept of spiritual leadership in the country's nursing context, and identify its aspects from nurses' and nursing managers' perspective to identify the factors and elements that are effective in the application of spiritual leadership in nursing by discovering the meaning and nature of spiritual leadership. Moreover, the correspondence between the concept of spiritual leadership in the organizational context of the Iranian nursing community and its concept in Fry's spiritual leadership model should be verified to prepare the floor for the application of this model in the Iranian sociocultural context and in the nursing profession. One way of recognizing and explaining the aspects of a concept based on the context of occurrence of a phenomenon, is qualitative content analysis. This method is used when there is not sufficient knowledge available on the issue under study or there is no general consensus on it. Hence, since spiritual leadership is a new concept and all its dimensions are not fully known yet, content analysis method was used (21). Qualitative content analysis permits the researchers to interpret the originality and reality of data subjectively, yet scientifically. The goal of content analysis study is to offer a knowledge of experience related to a certain phenomenon providing a deeper perception of the phenomenon under study (22). Consequently, this study aimed at elucidating the concept of spiritual leadership in the cultural context and working conditions of Iranian nurses via content analysis approach.

\section{Material and Methods}

\subsection{Research design and participants}

This qualitative content analysis study was conducted to identify the concept and dimensions of spiritual leadership in a nursing context using a directed content analysis method based on Fry's spiritual leadership theory (21). This study was accomplished at three universities of medical sciences in Tehran from October 2015 to March 2016 . The participants $(\mathrm{n}=14)$ consisted of nursing staff and managers working in teaching hospitals, and were selected with purposive sampling method noting a maximum variation (i.e., sex, age, level of education, work experience). The study's inclusion criteria required participant nurses to have at least two years of work experience in different shifts and to be a member of the nursing staff, while participants who were nursing managers were required to have two years of management experience in organizational positions.

\subsection{Interviews and data collection}

Before starting interviews, each participant was given assurance regarding confidentiality, and informed written consent was obtained, to record their voice on audiotape. Data were collected using in-depth semi-structured 
interviews conducted in quiet private locations at their working units, in accordance with participants' wishes. According to directed content analysis approach, the interview began with a broad opening question: "Please tell me about your experiences with nursing leadership at work." Then, the interview continued by specific questions based on the goals of the study. Some questions in this regard included: "As the team leader, how do you guide your staff to achieve organizational goals?", "What's the meaning of spiritual leadership in nursing in your viewpoint?", "Have you ever had a spiritual leader in your organization? What are some of their characteristics?", "As a nursing manager, how do you use the goals and vision of the organization to promote the personnel's revenue?" (Question related to managers), what is your role in team work or how do you feel about working in a team? Does your manager attend to your needs?" (Question related to personnel). The researchers tried to have minimal intervention in the course of the interview. Yet, they prevented the diversion of the interview course by asking appropriate questions. Moreover, by co-constructing the interview with respect to Fry's spiritual leadership model, the course of the interview progressed towards covering the research goals. Exploratory co-constructive questions on the basis of the information provided by the participant and also clarifying questions like: "Can you explain more?", "What do you mean?", "Can you give me an example so that I can better understand it?" were asked to clarify the topic under study. At the completion of each interview, it was listened to as soon as possible and then the content was transcribed verbatim using Microsoft Word. On the whole, 14 interviews were performed with 14 participants each lasting between 30 to $60 \mathrm{~min}$ with a mean length of $40 \mathrm{~min}$. Data collection continued until information saturation was achieved (22). In this study, data saturation was achieved at the completion of the 11th interview so that no new data could be gained any longer. Only the previous data were repeated and approved. However, to make sure of data saturation, three further interviews were performed so that a total of 14 interviews with 14 participants were done and no participant was interviewed twice. Each interview was transcribed verbatim according to Graneheim and Lundman (2004) (23). The unit of analysis consisted of all interviews. The researchers read the interviews several times after transcription, and the units of meaning were extracted from them to find initial code. Data organization and analysis were conducted using MAXQDA-10 software. During the process of continuous comparative analysis, relevant codes were compared regularly and were checked with the data. Then, according to the constructs of the spiritual leadership model, the sub-categories and categories were developed (21).

\subsection{Accuracy and stability of data}

In this study, to ensure of accuracy and stability of data, credibility, dependability, transferability, and confirmability, considered as scientific accuracy criteria in qualitative studies and introduced by Lincoln \& Guba (1989), were considered (24). Credibility was established through a variety of participants with respect to age, gender, work experience, ward diversity, various managerial levels, also frequent reviewing and revision of data and data immersion, interaction with participants, and reviewing and revision by research team. Also, to establish the validity of data, member checks were performed by four interviewees as investigating the coding obtained from interviews and subcategories. Moreover, to make sure of accuracy in data interpretation, the findings were peer checked by experts in the field of qualitative research, and the required corrections were made using their suggestions. Regarding transferability, an attempt was made to clearly describe all the details of the study including the context of the study and characteristics and experiences of the participants, and a comprehensive report on the complete details of the research process was given. Also, all the documents and evidence were preserved for future reference.

\subsection{Ethical Considerations}

To observe ethical codes of research, approval of Committee of Ethics in Research at medical universities of Tehran was obtained under no. SBMU2.REC.1394.116, dated 28.9.2015 and the required permissions were acquired from universities of Tehran. Then, the research goals and procedures were explained to the participants, and oral and informed written consents were obtained from each participant. They allowed the researcher to record their interviews and were assured of confidentiality and anonymity of their information, and could leave the study voluntarily at any stage.

\section{Results}

In this study, 14 nurse and nurse managers participated and were interviewed. Eleven of them were female and three were male, with an age range of 26 to 52 years and a mean work experience of 13 years. Nine participants held BS, four MSc, and one with PhD degree. Four of them were nursing managers, four head nurses, and six nurses. In analyzing the interviews, after the removal of duplicated codes and merging them, 33 sub-categories representing nine categories were observed. The analysis also identified three main categories based on Fry's spiritual leadership model, including "spiritual leadership", "spiritual well-being", and "organizational outcomes" (Table 1). 
Table 1. Main categories, categories and subcategories of spiritual leadership in nursing

\begin{tabular}{|l|l|l|}
\hline Main categories & Categories & The sub-categories \\
\hline \multirow{5}{*}{ Spiritual leadership } & Vision / forethought & $\begin{array}{l}\text { Knowledge of the Leader, Wisdom of the Leader, Spiritual } \\
\text { purpose, Lightening the way, Achieve Desired goals }\end{array}$ \\
\cline { 2 - 3 } & Altruistic love & $\begin{array}{l}\text { Attention to the staff, Humanistic characteristics of spiritual } \\
\text { leader, Justice }\end{array}$ \\
\cline { 2 - 3 } Spiritual well-being & Hope/faith & $\begin{array}{l}\text { Spiritual belief, Faith in a higher power, Hope, Perseverance, } \\
\text { Development of objectives and innovation }\end{array}$ \\
\cline { 2 - 3 } & Meanbership & $\begin{array}{l}\text { Group Satisfaction, Employees trust in their leader, Teamwork, } \\
\text { Mutual Understanding }\end{array}$ \\
\cline { 2 - 3 } & $\begin{array}{l}\text { Pleasant Environment, Love to work, Delivering value and } \\
\text { meaning to work, Life Meaningfulness }\end{array}$ \\
\cline { 2 - 3 } & $\begin{array}{l}\text { Extrinsic Motivation } \\
\text { Organizational } \\
\text { Learning }\end{array}$ & $\begin{array}{l}\text { Acquiring knowledge from various sources, Collaborative } \\
\text { learning, Supporting learning }\end{array}$ \\
\hline Organizational \\
outcomes & $\begin{array}{l}\text { Organizational } \\
\text { Commitment }\end{array}$ & $\begin{array}{l}\text { Normative commitment, Emotional commitment, Continuous } \\
\text { commitment }\end{array}$ \\
\cline { 2 - 3 } & $\begin{array}{l}\text { Organizational } \\
\text { Productivity }\end{array}$ & \begin{tabular}{l} 
To achieve peace, Improving the quality of services \\
\hline
\end{tabular} \\
\hline
\end{tabular}

\subsection{Spiritual Leadership}

Spiritual leadership was the first main category obtained in this study. It consists of values, attitudes, and behaviors which are necessary for creating motivation in oneself and in others so that individuals may enjoy spiritual wellbeing through feelings of meaningfulness at work and sense of community (25). This main category consists of three categories of vision, altruistic love, and faith / hope.

3.1.1. Vision:

Vision refers to what the organization seeks to attain in the future. On the basis of the results of this study, "vision" includes 5 subcategories:

a) Leader's knowledge

The nurse leader should possess knowledge and expertise. One of the female nurses with 17 years' work experience claims in this regard: "The nursing leader should be up-to-date, and I think she should be first in everything, even in minor tasks" (Participant \#5).

b) Wisdom

The nurse leader should possess sagacity and wisdom in addition to knowledge and expertise. We call a person sage if they have the right perception of nursing issues and are able to analyze the conditions, finding the possible solution in the shortest time possible. One of the male nursing managers says in this regard: "It is owing to wisdom that a manager is successful in the field of spiritual leadership, since through wisdom, humans do not limit things to corporeal powers. Wisdom enables her/him to analyze the situation and come up with the best solution" (Participant \#8).

c) Lighting the way

One of the important characteristics of spiritual leaders in nursing is the clarification of the path to achieving goals. Another head nurse with 21 years' work experience asserts: "First I should recognize the goal myself; then, if the goal is clear for me, I should clarify it to my personnel. Well, I should make them understand that our first priority is the patient...then, we should demonstrate the path to this goal for them..." (Participant \#7).

d) Spiritual purpose

People try to achieve a valuable goal, a goal that gives them the energy required for continuous activity; achieving a spiritual target and obtaining God's satisfaction may be a landscape of nursing." One of the male nursing managers stated in this regard: "To please God could be our vision. To reach satisfaction, peace, hope, and patience... that could be our vision." (Participant \#8).

e) Achieving the desired goals

The nurse leader always tries to enable the nursing team to achieve its goals". One of the head nurses with 23years' work experience explains the way of achieving one of his goals ( $\% 0$ rate of bedsore in the ward) in this way: "Now, we have $\% 0$ of decubitus ulcers in our ward. Most of the patients with bedsore come 
from outside the hospital. We don't have them in the ward. I mean we stabilized the issue of the "change position" of the patient" (Participant \#1).

\subsubsection{Altruistic Love}

In nursing spiritual leadership, altruism consists of a sense of unity, coherence, and well-being which is generated by caution, worry, and gratitude for both the self and others. "Altruistic Love" includes three subcategories:

a) Attending to the staff

Participants believed that spiritual leaders in nursing attends to their personnel, and shows this in various ways. Another nurse with 20 years' work experience says: Many times, when I or my kids have been ill, my ward nursing manager would phone to tell me not to come to work, and that she would do the best she could, without me asking her" (Participant \#14).

b) Humanistic characteristics of spiritual leadership

The spiritual leader is equipped with some admirable features. The most important features are kindness, sympathy, honesty, bravery, integrity, confidence, loyalty, and modesty." Another nurse with 10 years' work experience says: "The leader must be honest and trustworthy." (Participant \#13). Another participant stated: "A spiritual leader forgives others, he is kind, nice, and befriends his employees." (Participant \#12).

c) Justice

Justice means placing everything in its right place. The participants believed that spiritual leader in nursing should observe equity in all areas. Another female head nurse postulates in this respect: "Another thing that is very important is that a spiritual leader should be fair in rewards or promotions. I mean she should treat personnel fairly. Fairness does not mean that everyone is equal; it means people should be in their own right place" (Participant \#4).

\subsubsection{Hope/faith}

Nursing leaders promote faith and hope among their staff to achieve the goals of nursing. "Hope/faith" includes five subcategories:

a) Spiritual belief

The spiritual leaders themselves should have a deep understanding of spirituality, and should have internalized spirituality in themselves so that this concept streams in their behavior and leads the personnel in the path of spirituality. Another female nurse manager with 24 years' work experience declares in this regard: "The nurse leader must have defined spirituality for himself completely. He should recognize it. He should have a strong faith in it and adhere to it. Naturally, he should have admitted to the world of spirituality. Also, he should have worked in a spiritual atmosphere and must have learned this climate. $\mathrm{He}$ should learn to work to achieve spirituality" (Participant \#8).

b) Faith in a higher power

The first step in spirituality is the acceptance of a higher power (God) in human life and the universe. Leaders promote faith in a higher power. The higher power means that this power supervises human behaviors and supports humans in achieving goals. Participant No. 9 (A male nurse with 5 years' work experience) stated that, "Belief in spirituality and God is very effective in promoting higher performance. I believe that a leader must recognize a higher power supervising his work."

c) Hope

Hope is an enthusiastic desire of something that we anticipate to have. The nurse leader always keeps the hope for future alive in nursing. One female nurse with 7 years' work experience says in this relation: "I feel when I do something for a patient, the patient's prayers accompany me. From that perspective, it's very important to me and motivates me, because I feel that I will be rewarded in the other world." (Participant \#11)

d) Perseverance

One property of spiritual leaders in nursing is "resistance". There are many people who deal with important affairs enthusiastically, yet, they lose the initial enthusiasm after some time and leave the work imperfect. A spiritual nurse leader is intrepid and resistant in the face of great problems". About commitment and resilience of leaders in supporting personnel, participant \#3 (a chief nursing officer) argued: "Everyone knows that the chief nursing officer is like an eagle. No one is allowed to dish out punishment for a mistake made by personnel; they should come and tell me first. Perhaps they can do that in other departments, well that is up to them, but not in nursing".

e) Developing goals

A spiritual leader should develop targets and innovation, so that the nursing team can be creative and innovative, which results in synergic organizational innovation. Another nurse manger with 19 years' work experience expresses his opinion like this: "Everyone knows that my style of work is not traditional; I had a 
new idea every day. I had new ideas in the 8 years working as a training supervisor. Everyone knows that since I have become a chief nursing officer, I have done my best to improve things" (Participant \#3).

\subsection{Spiritual well-being}

The second main category in the model of spiritual leadership is spiritual well-being. Spiritual well-being is defined as a sense of transcendence, calling, and need for social connections or membership in organizations (15). This main category consists of four categories:

\subsubsection{Membership}

Membership is a sense of understanding and respect which arises, to a large extent, from relationship and connections to group interactions that occur as a part of membership in groups. Membership consists of four subcategories

a) Group satisfaction

Spiritual leadership leads to personnel's satisfaction. The staff's satisfaction makes them feel that they are a member of the team in the organization". A male nurse with 5 years' work experience says: "When the nurses or patients see that the organization is working to the best of its capacity to satisfy the personnel, this leads to greater satisfaction of the clients" (Participant \#9).

b) Employee trust in their leader

The spiritual leadership approach drives the nurses to confide in their leader and the hospital. Nurses' confidence in nursing management is mandatory for the interpersonal relations, nursing efficacy, and sense of community. Regarding personnel's trust in a spiritual leader, participant \#7 (a head nurse) explained: "My personnel can trust me here. They can discuss their problems, and they know that their word would not be spread".

c) Teamwork

Spiritual leaders in nursing render team work as important. In a spiritual organization, the tasks are carried out as team work collectively and collaboratively. Participant \#6, a head nurse, asserts about team work in his own ward: "All our tasks are collaborative. After setting up goals and plans with the participation of all of the employees, we all cooperate so as to achieve our goals."

d) Mutual understanding

We should keep in mind that respecting the other party and considering their attitudes and opinions in treating others and in communicating with them, is the most important point. In a hospital where spiritual leadership is flowing, nurses and leaders have mutual understanding of each other. One of the chief nursing officers asserted in relation to the mutual understanding between leader and personnel: "When writing the monthly schedule, I put the schedule in the middle and tell everyone that we have a problem concerning 2 or 3 people needing time off at the same time, and that this is a problem. Then, personnel talk among themselves for a while, and eventually the person that does not desperately need time off volunteers to cover such and such a shift. Then, everything is alright, and I try to make up for the favor" (Participant \#6).

\subsubsection{Calling/Meaning}

Fry (26) defined calling as "Calling refers to how one makes a difference through serving others and, in doing so, finds meaning and purpose in life."(p. 703). In the meaningfulness category, four subcategories emerged:

a) Pleasant environment

The spiritual leader in nursing creates a pleasant climate in which nurses obtain feelings of meaningful work and sense of community. Participant \#6 stated about a pleasant working environment: "Many of my coworkers state that we show up eager for work. We know that we are going to an interesting place. This is also true for me. I mean, if I do not come to work and am unable to see my fellow workers for two days, I really miss the ward and my friends in the staff."

b) Love to work

A spiritual leader generates enthusiasm for work, so that personnel always love their jobs. In this respect, participant 11 (One female nurse with 7 years' work experience) described: "My ward nurse manager makes me truly love nursing. My job is so enjoyable, and I feel that God is pleased with us, and also we alleviate patient's pain. It is so pleasing when a patient recovers. Nothing is more pleasing than seeing that your patient is getting well".

c) Delivering value and meaning at work

Nurses with spiritual leadership feel that their work is meaningful and has value and direction. This issue is specifically manifested in nursing which deals with human beings. One of the experienced nurse managers says in this respect: "A spiritual perspective gives meaning to our work and is indeed our navigator. It can 
turn our limited and small goals into great ones. It can also turn our common, repetitive, and low value work into a holy, meaningful, and high-value work." (Participant \#8).

d) Life meaningfulness

Participants in the present study stressed that the spiritual leader makes personnel's lives meaningful. A participant commented: “A spiritual leader makes one's life scented and colorful and gives it direction. Spirituality in the workplace means everything; the dimension of our existence that does not disappear with death; the dimension that influences the world. I believe spiritual dimension is life itself' (Participant \#13).

\subsubsection{Extrinsic Motivation}

Extrinsic motivation of employees is one of the concepts that was emphasized by the participants in this study, although the spiritual leadership model of Fry is based on intrinsic motivation. Participants believed that spiritual leaders, along with creating intrinsic motivation in employees, should also make use of the extrinsic motivation in nursing employees due to the effectiveness of this motivational approach. Participants in the study emphasized material incentives, working conditions, communication, and visibility of employees. Material incentives are considered as one of the motivational factors that the leader could use in order to motivate nursing staff. In the extrinsic motivation category, four subcategories emerged:

a) Material incentives

Material incentives are considered one of the motivational factors that the leader could use in order to motivate nursing staff. In this regard a staff nurse stated: "Well, financial motivation is also important such as salaries and benefits. I feel if I do something and receive a good salary for it, this motivates me. Material aspects on one side, spiritual ones on the other side." (Participant \#10).

b) Working conditions

A nursing leader creates a pleasant and peaceful atmosphere in the workplace for personnel, one of the chief nursing officers said: "At work, we are not like colleagues; we are members of a family. We all try to give a helping hand to each other. Our patients always tell us that we should assume that a patient is one of our family members" (Participant \#6)

c) Communication

In an organization with spiritual leadership, personnel have a good relationship with one another and with themselves. Participant \#10 (a staff nurse) explained: "The ward nursing officer should have a friendly relationship with personnel; one that is unlike a boss-employee relationship. She should have a close relationship with personnel so that both patient-care duties are performed well and personnel are happy to work in that ward".

d) Visibility of employees

Another need of employees is to be attended by their leaders. It is an affective factor that motivates employees. Participant \#7 (a head nurse) said on this topic: "Staff expect to be recognized when they do their work, even if there is no other encouragement or persuasive strategies being used, employees must be at least verbally acknowledged. Staff are not acknowledged verbally many times."

3.2.4. Organizational Learning

Organizational learning cannot be found in Fry's spiritual leadership model, but is discussed in many studies (18, 27). This concept was also emphasized by participants in this study. In the Organizational learning category, three subcategories emerged:

a) Acquiring knowledge from various sources

Nursing requires continuous learning for its survival and development. In a learning organization, people seek out knowledge from multiple sources. Participant \#3 (a nursing manager) pointed out the importance of benchmarking for learning and improving organization in this regard: "We want to form a research team. This research team will research other hospitals to identify best practices that can be applied here."

b) Collaborative learning

In the organization with spiritual leadership, individuals help each other to learn and share what they have learned. Regarding learning from each other, participant \#2 (a chief nursing officer) said: "It is a kind of art that personnel learn how to interact with each other, and how to relate to each other".

c) Supporting learning

In an organization with spiritual leadership, the leader supports the nurses' learning, and provides the conditions required for facilitating nurses' learning. One of the female nurses with 17 years' work experience claims in this regard: "My head nurse (nurse director) must recognize my problems and guide me when solving them, and will help me take more specialized training classes, through an educational supervisor." (Participant \#5). 


\subsection{Organizational Outcomes}

Organizational outcomes is the third main category, which, in the view of Fry et al. (8), creates high levels of productivity and commitment from the outcomes of spiritual leadership. In the Organizational learning main category, two categories emerged:

\subsubsection{Organizational Commitment}

One of the outcomes of Fry's spiritual leadership model as well as the findings of this study, was the sense of commitment and employee dependability to organization. In the Organizational commitment category, three subcategories emerged:

a) Normative

Nurses who are governed by a spiritual leadership approach in their work, are committed to loyalty to an organization and feel a duty to support the organization. Participant \#2 (a chief nursing officer) described commitment of a member of personnel who intended to quit the organization, but through spiritual leadership, decided to stay: "Her colleague asked her if she wanted to leave this hospital, and she replied that she had spoken to the new chief nursing officer and found that she listened to what I had to say, and respected personnel; so, I calmed down and decided to stay".

b) Affective

Emotional commitment is an attachment that employees feel toward the organization. Participant \#11 (One female nurse with 7 years' work experience) said in this regard: "The type of management in my ward is such that even when I am sick, I will take a pill to make sure I can be present at the patient's bedside."

c) Continuous

One of the participants (a ward nursing manager) relayed: "It meant everything to me when a nurse was getting married and had to move to another town, and sobbingly said that she did not want to leave this ward". (Participant \#1).

\subsubsection{Organizational Productivity}

The second outcome achieved by a spiritual leader, is productivity and continuous improvement in the organization. This category has two subcategories:

a) achieving peace

Spiritual leadership in nursing will lead to mood and personality improvement in the staff and increase their sense of acceptance and inner satisfaction. These changes can occur in such a way that staff have a sense of peace and reconciliation towards professionals, people, and God. One of the participants (a ward nursing manager) stated: "When I got into this section, there was a very jerky climate. There were colleagues who were very nervous, with a bad behavior. I waited and gave them time. Later, they found that I'm not pessimistic and understand, and cooperated with them. All the people love and accept truth. Now, there's a good condition, thank God, I'm satisfied. Colleague relations are good and the ward is calm. " (Participant \#1)

b) Improving quality of service

Nursing leaders with a spiritual approach in their system can provide a significant impact on better quality services to their clients. One of the head nurses said with regard to this concept: "With spiritual leadership, the work speed gets faster, a great climate comes to exist, and also, higher quality of nursing care can be provided." (Participant \#5).

\section{Discussion}

This study intended to explore meaning and dimensions of spiritual leadership from the perspective of nurse managers and staff. The results of this study showed that spiritual leadership in nursing, based on Fry's spiritual leadership theory, contains three main categories of "spiritual leadership," "spiritual well-being," and "organizational outcomes." Each main categories contains multiple categories. Spiritual leadership has the three categories of "vision, altruism, and faith and hope"; spiritual well-being has four categories including "meaning, membership, extrinsic motivation, and organizational learning"; and organizational outcomes contains two categories: "organizational commitment, and organizational productivity". In the field of spiritual leadership in nursing, according to Fry's leadership model, vision is an essential feature that the leader should use (7). Nelson (13) also states, in line with the present study, that spiritual leaders should provide a vision for employees so that they know about where the organization aims to go. The findings of Memarian et al. (28) also showed that the spiritual leader must specify a vision and goals and provide guidance to the employees. Participants in this study said that the spiritual leader should possess expert knowledge, wisdom, and sagacity, although these concepts were not explicitly mentioned in Fry's model. In this study, it became clear that altruism, which Fry (26) mentioned, is one of the most important attributes for spiritual leadership in nursing. Kindness, empathy, honesty, patience, courage, integrity, 
trust, loyalty, and humility are the key traits associated with the spiritual leader in this study. In the present study, participants also associated spiritual leadership with justice and acknowledgement of employees, which is consistent with the results of prior studies that emphasized the influence of organizational justice on the well-being and performance of nurses (29) and their quality of working life (30). Faith and hope, in the findings of this research, is also in alignment with the definition of faith and hope by Fry et al. (7). However, in this study, the main source of faith and hope includes spiritual belief, faith in the higher power, and expecting a reward by a higher power, which is slightly different from Fry's model. In Fry's spiritual leadership model, hope is the enthusiasm for what we expect to be realized, and faith is based on values, attitudes, and beliefs that result in confidence in the wishes and their realization (15). Nelson's study (13) aligned with the present study, confirms the relation of hope with a higher power. The development of objectives and innovation performed by the spiritual leader was reported in this study, consistent with the Fry' view (26). However, in the perspective of nurses in this study, the spiritual leader is a "supreme leader" who always keeps faith and hope alive in the organization. In the field of spiritual well-being of employees, people should move from self-oriented perspectives toward other-oriented perspectives to achieve a higher purpose and serve the common interests (25). In this study, participants expressed that due to the nature of their profession, nurses have to work in groups and have mutual understandings, which is also referred to as membership in the studies of Fry (26). Sweeney and Fry (25) also emphasized that spirituality has been empirically linked to a number of psychological health and well-being outcomes. Sohmen (31) and Nelson (13) also showed that participatory management is an important factor in spiritual leadership. In addition, in this study, participants emphasized that their trust in the leader and the leader's ability to create satisfaction among employees, were important factors for the spiritual leadership of an organization. According to the participants, in the context of a pleasant working environment, the nurses desired a love of their work, feeling they have a meaningful life. In this regard, Duchon and Plowman (32) believe that people not only seek a meaningful life, but also look for job meaningfulness. Polat (33) also states that spiritual leadership leads to the meaningfulness of the job, for people. Sendjaya (34), in a study aimed at conceptualizing and measuring the organization's spiritual leader, emphasized the meaningfulness and purpose in life that are consistent with the findings of this study. Fry's model is based on the intrinsic motivation of employees, so that he believes that a spiritual leader with a focus on intrinsic motivation of employees, increases organizational positive outcomes $(7,26)$. In this study, findings focused on intrinsic motivation, but there were observed effects of extrinsic motivation among nursing employees, as well. These forms of extrinsic motivation which occurred in the context of Iranian organizational culture such as improving the working environment, wages and benefits, relations between people, and employee visibility are also emphasized as factors that can motivate employees. Participants expressed that because of the nature of their profession, nurses must have a good relationship with each other and with their leader. Few studies have been carried out with respect to the extrinsic motivation, leadership, and spirituality with organizational outcome variables such as commitment. Anane (35) is one of the few researchers who has studied the relationship between spiritual leadership and extrinsic motivation and found that spiritual leadership (altruism and membership) is effective with the combination of extrinsic motivation on organizational commitment. Nelson (13) indicated that communication with employees is an important factor in spiritual leadership, similar to the findings of this study. Organizational learning is another concept that has been emphasized in spiritual leadership of nursing. Participants in this study expressed that in an organization with spiritual leadership, employees seek knowledge from different sources. Employees learn from each other, leaders make efforts to promote continuous learning among employees, and the organizational environment is supportive of learning. In support of the present findings, Fry (26) points out that the spiritual leader is indispensable for the development and continuous success of a learning organization, although learning is not mentioned as one of the main concepts in the spiritual leadership model. The study findings of Jeon (27), and Aydin and Ceylon (36), also suggest that spiritual leadership has an important positive influence on organizational learning. With respect to organizational outcomes, participants believed that spiritual leadership leads to normative, emotional, and continuous commitment in employees, which is consistent with Fry's spiritual leadership model and results of his studies, as well as the findings of other studies that have used his model $(18,19,37)$. As one of the strong points, this study dealt with determining the spiritual leadership and its dimensions from a perspective of both managers and nurses. As a weak point, the findings of this study demonstrated that this study was performed to emphasize the role of nursing leaders in clinical setting, but it did not examine nursing leader roles in education, research, and public health. Therefore, it is suggested that future studies examine the concept of spiritual leadership in these domains. Findings related to organizational outcomes in this study, such as improving service quality and productivity, are in accordance with Fry's studies $(7,15,26)$. 


\section{Conclusions}

Spiritual leaders in nursing can achieve the organizational goals by attending to the elements of extrinsic motivation and organizational learning in addition to intrinsic motivations of personnel. They can expand the individual and organizational outcomes by attending to elements of extrinsic motivation and organizational learning. The applied significance of these findings is that nurse leaders are capable of applying this style of leadership in the health-care system of the country to expand the individual and organizational consequences in nursing through noticing the concept and aspects of spiritual leadership in the organizational context of Iranian nursing community. It is recommended that, seeing the consequences of this new style of leadership and its importance in motivating the nursing personnel, nursing policy-makers provide the required conditions for education, and establish it in the Iranian nursing community to develop the nursing profession and promote the satisfaction of the people who are receiving the nursing services. Conducting some action research on the application of this style of leadership in the nursing community may pave the way for future research in this field.

\section{Acknowledgments:}

This paper was a part of the Ph.D. dissertation research project with the Research Council of Shahid Beheshti Medical University. All professors, managers, and nursing colleagues who were involved in this study are honored. We want to express our appreciation to professor Fry for his kind advice in this study.

\section{Conflict of Interest:}

There is no conflict of interest to be declared.

\section{Authors' contributions:}

All authors contributed to this project and article equally. All authors read and approved the final manuscript.

\section{References:}

1) Robbins S, Judge T, Millett B, Boyle M. Organisational behaviour. AU: Pearson Higher Education; 2013.

2) Radovich P, Palaganas J, Kiemeney J, Strother B, Bruneau B, Hamilton L. Enhancing leadership orientation through simulation. Crit Care Nurse. 2011; 31(5): 58-63. doi: 10.4037/ccn2011463. PMID: 21965384.

3) Fry L, Matherly L. Spiritual leadership as an integrating paradigm for positive leadership development. International Gallup Leadership Summit. Washington; 2006.

4) Tiew LH, Creedy DK. Development and preliminary validation of a composite Spiritual Care-Giving Scale. Int J Nurs Stud. 2012; 49(6): 682-90. doi: 10.1016/j.ijnurstu.2011.11.014. PMID: 22197053.

5) Kim S, Miles-Mason E, Kim C, Esquivel G. Religiosity/spirituality and life satisfaction in Korean American adolescents. Psychology of Religion and Spirituality. 2013; 5(1): 33-40.

6) Fry L. Spiritual leadership: State-of-the-art and future directions for theory, research, and practice. Spirituality in business Springer. 2008; 106-24.

7) Fry L, Latham JR, Clinebell SK, Krahnke K. Spiritual leadership as a model for performance excellence: a study of Baldrige award recipients. JMSR. 2016; 15: 1-26. doi: 10.1080/14766086.2016.1202130.

8) Fry L, Matherly L, Ouimet J. The spiritual leadership balanced scorecard business model: the case of the Cordon Bleu - Tomasso Corporation. JMSR. 2010; 7(4): 283-314. doi: 10.1080/14766086.2010.524983.

9) Benefiel M, Fry L, Geigle D. Spirituality and religion in the workplace: History, theory, and research. Psychology of Religion and Spirituality. 2014; 6(3): 175-87. doi: 10.1037/a0036597.

10) Buchan J, Twigg D, Dussault G, Duffield C, Stone P. Policies to sustain the nursing workforce: an international perspective. Int Nurs Rev. 2015; 62(2): 162-70. doi: 10.1111/inr.12169. PMID: 25639942.

11) Aitamaa E, Leino-Kilpi H, Iltanen S, Suhonen R. Ethical problems in nursing management: The views of nurse managers. Nurs Ethics. 2016; 23(6): 646-58. doi: 10.1177/0969733015579309. PMID: 25899724.

12) Vesterinen S, Suhonen M, Isola A, Paasivaara L. Nurse managers' leadership styles in Finland. Nursing research and practice. 2012: 1-8. doi: 10.1155/2012/605379.

13) Nelson B. Spiritual leadership in healthcare College of Education and Behavioral Sciences Greeley. University of Northern Colorado: University of Northern Colorado; 2008.

14) Reimer - Kirkham S, Pesut B, Sawatzky R, Cochrane M, Redmond A. Discourses of spirituality and leadership in nursing: A mixed methods analysis. J Nurs Manag. 2012; 20(8): 1029-38. doi: 10.1111/j.1365-2834.2012.01480.x. PMID: 23151105.

15) Fry L, Hannah S, Noel M, Walumbwa F. Retracted: Impact of spiritual leadership on unit performance. The Leadership Quarterly. 2011; 22(2): 259-70. doi: 10.1016/j.leaqua.2011.02.002. 
16) Ayranci E, Semercioz F. The relationship between spiritual leadership and issues of spirituality and religiosity: A study of top Turkish managers. IJBMS. 2011; 6(4): 136-49. doi: 10.5539/ijbm.v6n4p136.

17) Jamaludin Z, Rahman N, Makhbul Z, Idris F. Do transactional, transformational and spiritual leadership styles distinct? : A conceptual insight. JIBE. 2011; 2(1): 73-85.

18) Torkamani Z, Naami A, Sheykhshabani S, beshlide K. The Effect of Spiritual Leadership with Organizational Commitment, Productivity and Knowledge Performance with Mediating Spiritual WellBeing and Learning Organization, in Employees of Bidboland Gas Company. International Journal of Psychology and Behavioral Research. 2015; 4(1): 133-43.

19) Jeon K, Passmore D, Lee C, Hunsaker W. Spiritual leadership: A validation study in a Korean context. Journal of Management, Spirituality \& Religion. 2013; 10(4): 342-57. doi: 10.1080/14766086.2013.801026.

20) Chen $C$, Yang C. The impact of spiritual leadership on organizational citizenship behavior: A multi-sample analysis. Journal of business ethics. 2012; 105(1): 107-14. doi: 10.1007/s10551-011-0953-3.

21) Elo S, Kyngas H. The qualitative content analysis process. J Adv Nurs. 2008; 62(1): 107-15. doi: 10.1111/j.1365-2648.2007.04569.x. PMID: 18352969.

22) Krippendorff K. Content analysis: An introduction to its methodology. Sage; 2004.

23) Graneheim UH, Lundman B. Qualitative content analysis in nursing research: concepts, procedures and measures to achieve trustworthiness. Nurse Educ Today. 2004; 24(2): 105-12. doi: 10.1016/j.nedt.2003.10.001. PMID: 14769454.

24) Streubert HJ, Carpenter DR. Qualitative Research in Nursing: Advancing the Humanistic Imperative. 5th edition. Philadelphia: Lippincott Williams \& Wilkins; 2011.

25) Sweeney PJ, Fry LW. Character development through spiritual leadership. Consulting Psychology Journal Practice and Research. 2012; 64(2): 89-107. doi: 10.1037/a0028966.

26) Fry L. Toward a theory of spiritual leadership. The Leadership Quarterly. 2003; 14(6): 693-727. doi: 10.1016/j.leaqua.2003.09.001.

27) Jeon K. The relationship of perception of organization performance and spiritual leadership, workplace spirituality, and learning organization culture in the Korean context: The Pennsylvania State University; 2011.

28) Memarian R, Ahmadi F, Vaismoradi M. The leadership concept in Iranian nursing. Int Nurs Rev. 2008; 55(1): 48-54. doi: 10.1111/j.1466-7657.2007.00587.x. PMID: 18275535.

29) Hansen N, Sverke M, Näswall K. Predicting nurse burnout from demands and resources in three acute care hospitals under different forms of ownership: A cross-sectional questionnaire survey. Int J Nurs Stud. 2009; 46(1): 95-106. doi: 10.1016/j.ijnurstu.2008.08.002. PMID: 18823625.

30) Hatam N, Fardid M, Kavosi Z. Perceptions of organizational justice among nurses working in university hospitals of shiraz: a comparison between general and specialty settings. Nurs Midwifery Stud. 2013; 2(4): 77-82. doi: 10.5812/nms.10637. PMID: 25414883, PMCID: PMC4228899.

31) Sohmen V. Leadership and teamwork: Two sides of the same coin. JITED. 2013; 4(2): 1-18

32) Duchon D, Plowman D. Nurturing the spirit at work: Impact on work unit performance. The Leadersh $Q$. 2005; 16(5): 807-33. doi: 10.1016/j.leaqua.2005.07.008.

33) Polat S. The level of faculty members' spiritual leadership (SL) qualities display according to students in faculty of education. Procedia Soc Behav Sci. 2011; 15: 2033-41. doi: 10.1016/j.sbspro.2011.04.049.

34) Sendjaya S. Conceptualizing and measuring spiritual leadership in organizations. IJBI. 2015; 2(1): 104-26.

35) Anane A. A Study of the Influence of Spiritual Leadership, Engaged Leadership and Extrinsic Motivation on Continuance Commitment in Ghanaian Banks University of Ghana: University of Ghana; 2015.

36) Aydin B, Ceylan A. The effect of spiritual leadership on organizational learning capacity. AJBM. 2009; 3(5): 184-90. doi: 10.5897/AJBM09.015.

37) Hunsaker W. Spiritual Leadership as a Universal Construct: An Empirical Study of Fry's (2003) Model of Spiritual Leadership in a South Korean Context: Regent University; 2012. 